hours, take no work home, take time off in lieu of any weekend work they have to do, refuse to use their home telephones for official calls and stop doing jobs which ought properly to be done by an officer of a higher grade. Unless there's an outbreak of foot and mouth, that is.

\section{Soviet breeder reactor accident}

\section{from our Soviet Correspondent}

RECENT unofficial reports, apparently based on data from United States satellites, indicate a serious accident to the Soviet fast breeder reactor $\mathrm{BN}-350$, which formed the heart of the new town of Shevchenko on the Mangyshlake Peninusular on the Caspian Sea.

The reactor was designed to power a desalination plant producing more than 100,000 cubic metres of fresh water a day and was intended to trasform the desert shore of the Caspian "where even the camels look weary" into a modern, industrial model township with a population of 80,000 , complete with parks, fountains and avenues of shady trees. The town was clearly intended to be a showpiece, and was accordingly named after the nineteenth century Ukrainian poet Taras Shevchenko, although the "drowsy waves, sky unwashed and dirty" and the "worthless sea" to which he was exiled was not in fact the Caspian but the Aral. Shevchenko was, however, a figure of world renown (even meriting a statue in Washington DC) and was considered a suitable eponymous hero for what was intended to become a showpiece of national and international importance.

Reports of the disaster pose some interesting problems when compared with the official publicity handouts. According to the Novosti Agency, the reactor, which was commissioned on September 27, 1972, was officially "launched" on July 16, 1973. Shortly afterwards an Izvestia correspondent visited the station and described in glowing terms the reactor with its control centre "like the bridge of an imaginary spacecraft". An influx of visitors was clearly expected-a special display showing a mockup of one of the fuel elements was exhibited in the entry hall. Even the Izvestia correspondent, however, noted the hazards of the "exotic coolant", molten sodium: but he stressed that special safety measures had been incorporated in the design.

The BN-350 was designed to operate on the three-circuit principle: in the first circuit the sodium flows directly round the fuel elements (steel "pencils" containing $6 \mathrm{~mm}$ pellets of uranium-235- enriched uranium) and itself becomes radioactive, giving off heat through the steel heat exchanger walls to the molten sodium and the second circuit which is heated to $450^{\circ} \mathrm{C}$. The sodium in the second circuit then heats the water in the third circuit in the usual way, producing a nominal 1400 tonnes of steam an hour. In all, the reactor has six such three-circuit loops. The total thermal power of the reactor is rated at 1 million $\mathrm{kW}(1 \mathrm{GW})$ which can be divided between electricity generation and desalination as required. Initially, an optimal regime of $150,000 \mathrm{~kW}$ of electricity and 12,000 tonnes of desalinated water a day was envisaged.

The reports and rumours of damage suggest that something has failed in the cooling channels-though whether this refers to the first or second sodium circuit is not definite. Clearly, either could cause the "large fire" which the satellite data are said to indicate: damage to the first circuit, however, would be far more serious, involving a considerably greater radiation hazard.

The most curious feature is the date of the alleged disaster. That generally

\section{Switched off in academe}

A suggestron that universities might lose their exemption from the working of the three-day week in Britain has been made in a memorandum issued to heads of departments and administrators at the University of Birmingham. Asking that the use of academic buildings in the evening and at night should be discouraged, the university's Estates and Buildings Officer, $\mathrm{Mr}$ J. H. Fathers, told members of staff that he was making the request as a result of an urgent message from the University Grants Committee (UGC).

"On Monday morning" the memo reads, "I received an urgent telephone call from the UGC telling me that the Department of Energy had contacted them to say that representations had been made about the excessive use of electricity in educational establishments. The department inferred that if this continued universities might be specifically placed under the regulations of the three dayweek Statutory Order".

The UGC said it had no knowledge of an urgent telephone call and the Department of Energy denied making any inference that universities might be subject to the Statutory Order. mentioned is July 1973, shortly after the official "launching". But as late as August 21, 1973 the Novosti agency issued a three-page report on the $\mathrm{BN}$ 350 , the "atomic heart" of the Mangyshlake Peninsular (a length of coverage normally given only to matters of major international importance). Either the satellite dating is incorrect, or the Novosti agency was particularly late in releasing information, or some attempt was made at a cover-up operation-a not unlikely contingency, in view of the prestige attached to developments at Shevchenko.

\section{Chemists think about energy}

Is Britain a group of top university chemists has been talking with scientists from Imperial Chemical Industries, British Petroleum and the Department of Energy in order to define long term prospects for evolving alternatives to fossil fuel supplies. The meeting followed an initiative by Professor R. Mason, Chairman of the Science Board of the Science Research Council (SRC), and among the academics brought in for the talks were Sir George Porter, Professor Sir Derek Barton and Professor Geoffrey Wilkinson. Similar discussions are likely to take place in other departments of the SRC, and a joint communique is expected in a month or so. In the meantime the Chemistry Study Group has issued the following statement:

"The Science Research Council has a broad responsibility for promoting research of 'timeliness and promise' which, together with its involvement in postgraduate education, can be expected to provide advances in fundamental scientific knowledge. However, within this general remit, the council is concerned to assess the balance of its funding pattern in relation to national needs or priorities. In common with many other scientific research funding agencies throughout the world, events of the past three months have caused it to take a new look at topies of research which may have a bearing on the energy situation.

A Chemistry Study Group of the Science Board (Secretary, Dr S. M. Mellows) has recently debated preliminary views of possible chemical innovation which might be applicable in the general context of energy supply. The Study Group accepted that any short term solutions to the problems in this area will most probably be based in industry, or, say, the Department of Energy rather than in the universities or polytechnics and, therefore, concentrated on longer term prospects such as the need for synthetic fuels in the year 